\title{
OPTIMAL WORK BREAKS IN DETERMINISTIC AND PROBABILISTIC REPETITIVE PROJECTS
}

\author{
Photios G. Ioannou \\ Chachrist Srisuwanrat \\ Civil \& Environmental Engineering Department \\ 2350 G.G.Brown, University of Michigan \\ Ann Arbor, MI 48109-2125, U.S.A.
}

\begin{abstract}
An effective way to reduce the duration and cost of projects with repetitive activities is through the relaxation of resource continuity and the introduction of work breaks at strategic points between repetitive project units. This paper describes the problem and introduces the basic concepts for determining the optimal location and duration of work breaks for both deterministic and probabilistic activity durations. The procedure is described in detail and is applied to an example project with 9 activities with probabilistic durations that repeat over 10 similar work units. The solution employs concepts from the Repetitive Scheduling Method (RSM), the Sequence Step Algorithm (SQS-AL), and is modeled in STROBOSCOPE, an activity-based simulation system. Numerical and graphical results explain the process and the underlying time and cost tradeoffs.
\end{abstract}

\section{INTRODUCTION}

Projects with repetitive units of similar work are quite common in construction. Examples include multi-story buildings, housing projects, highways, and tunneling projects. In these projects, the same activities are repeated from unit to unit by the same crews. For example, in a multistory building, one crew installs interior partition studs from floor to floor, while another crew follows and installs drywall. Of particular interest in scheduling repetitive multiunit projects is the ability to keep crews working continuously without interruption. Otherwise, crews experience periods of idle time where they receive pay without producing output. Thus, the uninterrupted (i.e., continuous) utilization of resources is of prime importance.

Scheduling repetitive activities with deterministic durations to eliminate resource idle time is accomplished through the Repetitive Scheduling Method (RSM) introduced in (Harris and Ioannou 1998). In contrast to the critical path method (CPM) which schedules activities at their early start resulting in resource idle time, RSM postpones activities from their early start date in order to keep re- sources working continuously and without interruption. Sometimes, however, resource continuity comes at the cost of an extended project duration as illustrated in Figures 1 and 2 .

Figure 1 is a production diagram that shows the CPM schedule for four activities (A, B, C, and D) that repeat over 4 identical project units. The resource performing activity B has a total idle time of 30 days caused by 3 interruptions (lags). Similarly, activity D also has 3 interruptions resulting in a total idle time of 45 days. Therefore, the CPM early-start schedule results in 75 days of total idle time and a project duration of 105 days.

Figure 2 shows a schedule using RSM that eliminates idle time by postponing activities $\mathrm{B}$ and $\mathrm{D}$ from their early start dates. A comparison of Figure 1 (CPM) and Figure 2 (RSM) shows that the introduction of resource continuity in RSM eliminates all 75 days of resource idle time, but also increases project duration from 105 to 135 days.

Typically, the cost savings due to the elimination of resource idle time is far greater than the additional cost due to increased project duration. Yet, in certain cases that may not be true. Delaying project completion may increase project indirect costs, may lead to opportunity costs, and may result in liquidated damages, all of which can lower overall profit. Accordingly, the tradeoff between eliminating resource idle time and increasing project duration must be analyzed carefully. The same holds for the possibility of eliminating idle time without increasing project duration.

Two strategies can be applied to RSM schedules to minimize the cost and schedule impact of lengthening project duration that result from having crews work continuously: balancing unit production rates, and the introduction of work breaks. The advantages and limitations of balancing production rates are well documented in the literature and are not repeated here. On the other hand, only a few studies consider the application of work breaks in repetitive projects, although as shown in this paper, this approach can be quite effective.

In this context, a work break is a time period when resources temporarily leave their project (or site) and do not 


\section{Ioannou and Srisuwanrat}

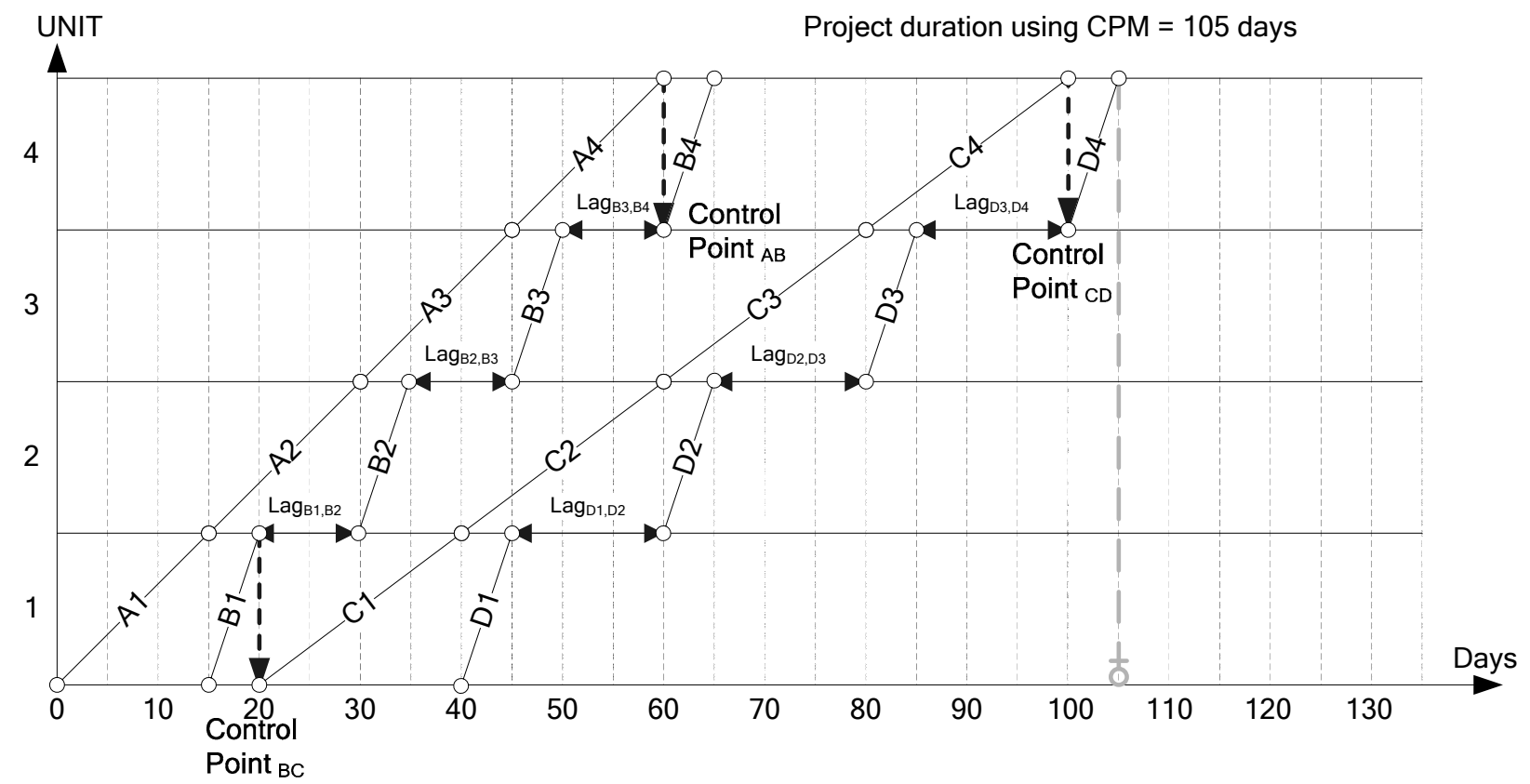

Figure 1: CPM early-start schedule has project duration of 105 days but also resource idle time of 75 days.

earn wages. In contrast, during idle time, resources are on site and being paid, even though they do not produce output. Accordingly, the costs associated with discontinuities due to work breaks and idle time are completely different. In particular, work breaks may introduce other costs such as the cost of transporting resources (labor and equipment), the cost of hiring and firing labor, the cost of setting up and dismantling equipment, etc. Also, the impact of set-up time after work breaks on project duration must also be evalu- ated. In this paper we focus primarily on the underlying tradeoff between total project idle time and project duration.

Figure 3 illustrates this tradeoff by introducing one of several possible work breaks in Activity B. In this case, the introduction of a 20-day work break between B2 and B3 reduces project duration from 135 days (obtained by RSM in Figure 2) to 115 days. Notice that in order to maintain resource continuity between $\mathrm{B} 1$ and $\mathrm{B} 2$, the start of activity

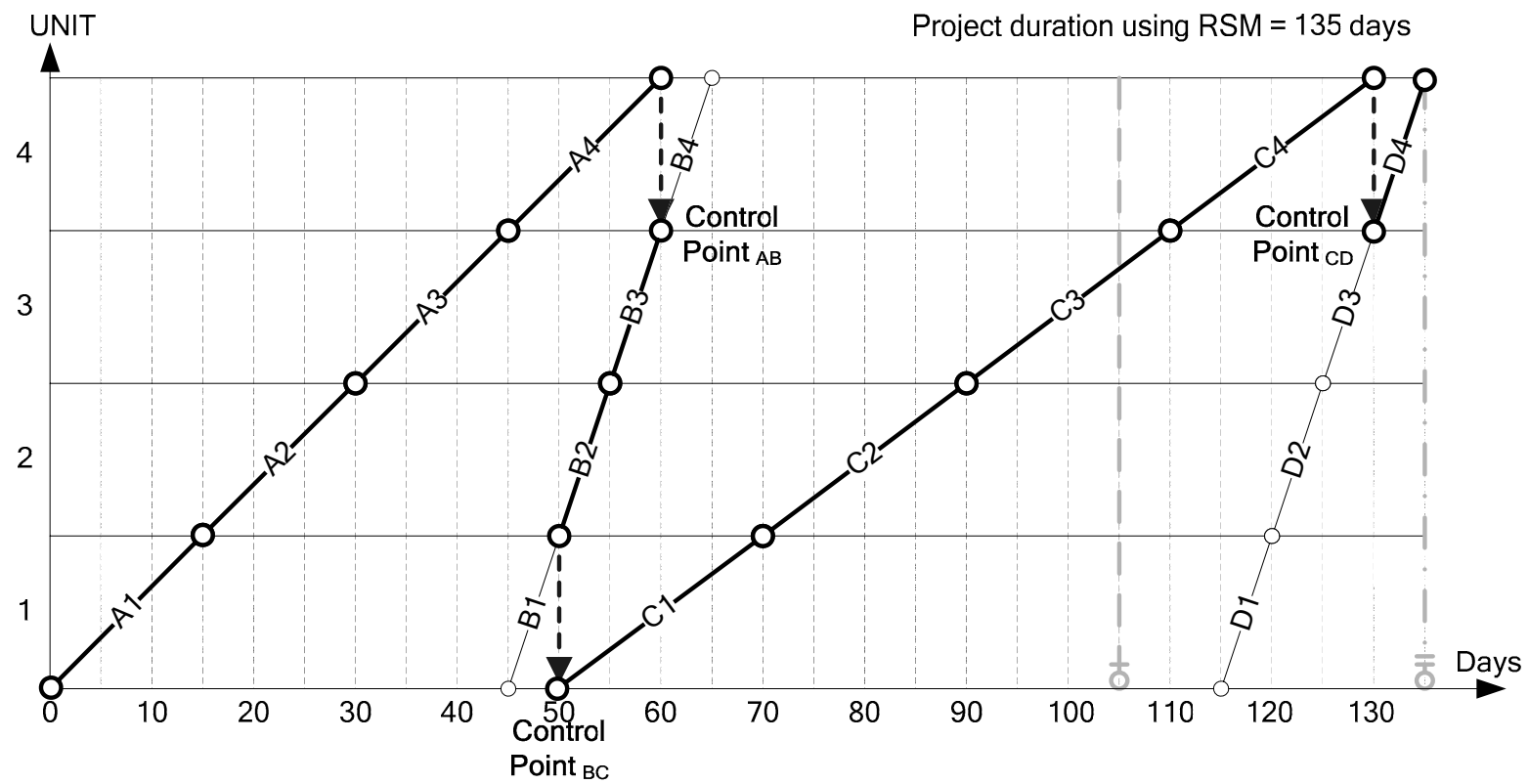

Figure 2: RSM eliminates resource idle time but increases project duration from 105 to 135 days. 


\section{Ioannou and Srisuwanrat}

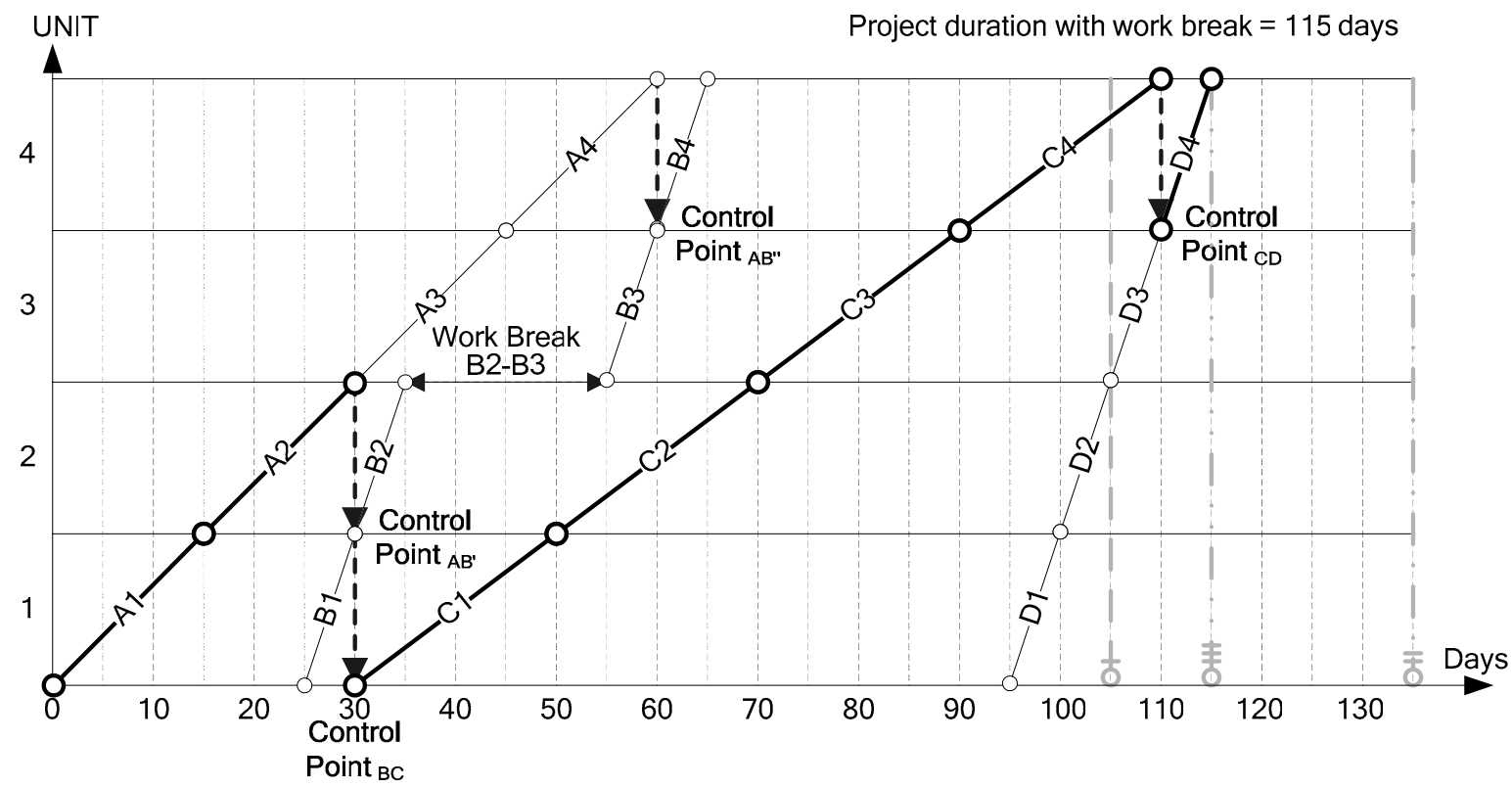

Figure 3: A work break between B2 and B3 reduces RSM project duration from 135 to 115 days.

B1 must be postponed from an early start date of 15 (Figure 1) to day 25, (Figure 3). Overall, the introduction of a 20-day work break in activity $\mathrm{B}$ reduces project duration also by 20 days, from 135 days (RSM schedule without breaks) to 115 days (RSM schedule with one break). Moreover, this schedule is only 10 days longer than the 105 days required by CPM while at the same time it eliminates the 75 days of resource idle time. Thus, it may be the best solution. These results are summarized in Table 1.

Table 1: Scheduling method, idle time and project duration

\begin{tabular}{|c|c|c|c|}
\hline Method & $\begin{array}{c}\text { Project Duration } \\
\text { (days) }\end{array}$ & $\begin{array}{c}\text { Total Resource } \\
\text { Idle Time } \\
\text { (days) }\end{array}$ & $\begin{array}{c}\text { Work } \\
\text { Break } \\
\text { Position }\end{array}$ \\
\hline CPM & 105 & 75 & None \\
\hline RSM & 135 & 0 & None \\
\hline RSM & 115 & 0 & B2-B3 \\
\hline
\end{tabular}

From this simple example it is clear that the following questions must be answered in order to schedule work breaks between units of repetitive activities:

- Which activity should be considered for the introduction of a work break (e.g., B)?

- Between which repetitive units should the work break be introduced (e.g., B2-B3)?

- What should be the start date of that activity in the first unit (e.g. B1)?

- How long should the duration of the break be?

In this paper we answer these questions for both projects with deterministic and probabilistic activity durations. We illustrate the proposed approach using an example pro- ject requiring 9 activities with probabilistic durations that repeat over 10 similar work units. The example is modeled using Stroboscope, an activity-based simulation system. The Sequence Step Algorithm, a simulation-based scheduling method for repetitive projects with probabilistic activity durations (Ioannou and Srisuwanrat, 2006) provides the fundamental underlying scheduling methodology.

\section{DETERMINING WORK BREAK POSITIONS}

The methodology for determining optimal work break locations within repetitive project schedules is based upon RSM scheduling concepts introduced in (Harris and Ioannou 1998). In particular, we shall use control points, the controlling sequence, and relative production rates to filter out activities and locations where the introduction of work breaks would not shorten project duration.

\subsection{Control Points and Controlling Sequence}

A control point between two repetitive activities (e.g., A and $\mathrm{B}$ ) is the critical precedence relationship that determines the earliest location of the successor activity (B) so that its resource (crew) may work continuously and without interruption. In Figure 1, for example, the control point between $\mathrm{A}$ and $\mathrm{B}$ occurs at the end of $\mathrm{A} 4$ and the start of B4. To maintain continuity in activity B, the start date of B1 must be delayed to date 45, as shown in Figure 2, so that activity $\mathrm{B}$ is scheduled through the control point A-B.

In resource-constrained schedules, such as those produced by the Repetitive Scheduling Method (RSM), the 


\section{Ioannou and Srisuwanrat}

concept of the critical path breaks down. In its place, Harris and Ioannou (1998) introduced the new concept of the controlling sequence, i.e., the sequence of activities that controls project duration under the constraint of continuous resource utilization (resource continuity). In Figures 2 and 3 , the controlling sequence is depicted using bold lines.

Formally, the controlling sequence is defined as the series of activities, from project start to project end, that navigates through control points from one activity to the next while maintaining precedence and resource continuity to determine minimum project duration (Harris and Ioannou 1998).

In CPM, activities on the critical path are critical and those not on the critical path are not. In contrast, in RSM the controlling sequence may include both critical and noncritical activities. Similarly, activities not on the controlling sequence may also be critical or non-critical. Thus, RSM has a total of four distinct activity classifications as opposed to the two in CPM.

The function of the controlling sequence is to schedule the work (prior to actual construction) so as achieve minimum project duration while maintaining resource continuity. Hence, the introduction of deliberate work breaks in activities on the controlling sequence will relax the continuity constraints and could recoup some of the increased project duration caused by resource continuity. The fundamental conclusion of this observation is that only repetitive activities on the controlling sequence must be considered as candidates for introducing work breaks. Activities not on the controlling sequence can be ignored.

By considering only activities on the controlling sequence, the number of candidate work break locations is reduced significantly. However, this is a necessary but not a sufficient condition. Not every activity on the controlling sequence can shorten project duration through the introduction of deliberate work breaks. The effectiveness of work breaks to shorten project duration also depends on the relative production rates between activities on the controlling sequence as explained below.

\subsection{Relative Production Rates}

The locations of control points in the Repetitive Scheduling Method (RSM) depend on the relative unit production rates between activities. Formally, RSM characterizes the relative production rates between a predecessor and a successor activity as either converging or diverging.

A converging relationship occurs when the unit production rate of the successor activity is greater than that of its predecessor. The control point between two repetitive activities with constant unit production rates and a converging relationship occurs in the last unit of the successor. For example, in Figure 2 the production rate of activity B is greater than that of activity A (converging relationship) and the control point between $\mathrm{A}$ and $\mathrm{B}$ is at the end of A4 and the beginning of B4.

Similarly, a diverging relationship between two activities occurs when the unit production rate of the successor activity is less than that of its predecessor. The control point between two activities with a diverging relationship occurs in the first unit of the successor. For example, in Figure 2 the production rate of activity $\mathrm{C}$ is less than that of $\mathrm{B}$ (diverging relationship) and the control point between $\mathrm{B}$ and $\mathrm{C}$ is at the completion of $\mathrm{B} 1$ and the start date of $\mathrm{C} 1$.

Figure 2 also shows that not every activity on the controlling sequence can shorten project duration through the introduction of a work break. For example, the introduction of a work break in activity $\mathrm{A}$ or activity $\mathrm{C}$ will lengthen rather than shorten the project, even though both are on the controlling sequence. On the other hand, the introduction of a work break in activity B does shorten project duration as shown in Figure 3.

To check whether the introduction of a work break in an activity on the controlling sequence can shorten the project, it is necessary to compare the production rate of that activity to the production rates of its direct predecessor and successor. Consider, for example, activity B in Figure 3. The fact that the relative production rates between $\mathrm{A}$ and $\mathrm{B}$ are converging, and the relative production rates between $\mathrm{B}$ and $\mathrm{C}$ are diverging, make it sufficient for a work break in $\mathrm{B}$ to shorten project duration.

First, the converging relationship between A and B allows activities B1-B2 to start earlier if a work break is introduced at the end of $\mathrm{B} 2$. Clearly, the relationship between A1-A2 and B1-B2 is still converging and thus the control point between them is at the end of $A 2$ and the start of B2. Thus, the introduction of a work break in B creates this new control point that allows B1 to start earlier. However, the fact that B1 is now scheduled earlier does not guarantee that the work break in B will result in a shorter project duration. It is necessary to check the relative production rates between $\mathrm{B}$ and its successor on the controlling sequence, i.e., activity $\mathrm{C}$.

The second requirement is the diverging relationship between $\mathrm{B}$ and $\mathrm{C}$ which enables activity $\mathrm{C}$ to start and finish earlier if a work break is introduced to activity B. Since the control point between $\mathrm{B}$ and $\mathrm{C}$ is at the start date of $\mathrm{C} 1$, starting B1 earlier moves the control point toward the project start date, resulting in an earlier start date for $\mathrm{C} 1$. Consequently, activity $\mathrm{C}$ would finish sooner and this shortens the project as well.

It is important to appreciate that project duration is shortened because activity $\mathrm{C}$ is on the controlling sequence and because it starts earlier in Figure 3 than it does in Figure 2. Clearly, the reduction in project duration is due to the earlier start and finish date of activity $C$, i.e., the successor to the activity to which the work break is introduced (i.e. activity B), and is not due to the work break itself. 


\section{Ioannou and Srisuwanrat}

From this discussion, we can summarize our findings as follows:

In order to shorten project duration by introducing a work break into an activity (e.g., B), the activity must be on the controlling sequence and must have both a predecessor (e.g., A) and a successor (e.g., C) both of which must be on controlling sequence, too. Moreover, it must have a converging relationship with its predecessor (i.e., A) and a diverging relationship with its successor (i.e., $C$ ).

Typically, the application of this rule reduces the number of candidate activities and work break locations to just a handful. The next step is to evaluate the effectiveness of these locations and work break intervals.

\section{DETERMINING WORK BREAK DURATION}

After the possible locations for work breaks are filtered down to only those that may indeed shorten project duration, each one must be analyzed to produce a new schedule and project duration. The schedule for a particular work break location provides the activity start date in the first unit and the optimal work break duration.

In the example shown in Figure 2, the filtered work break positions are the finish dates of B1, B2, and B3. To determine which position is the best for a work break in activity $\mathrm{B}$, each of them must be tested individually. In this case, it is not hard to see that the work break position that minimizes project duration is at the end of $\mathrm{B} 2$, as shown in Figure 3.

To construct a new project schedule for a particular work break location in an activity, the resource continuity constraints for that activity must be split into two sets: before the work break and after the work break. Thus, the resource idle times for that activity must also be grouped into two separated sets as well.

For example, in Figure 3, a work break is introduced at the end of B2. This means that resource B is scheduled to work continuously from B1 to B2 and then take a break at the end of B2. After the break, resource B will return and work continuously from B3 to B4. In this case, the sum of idle times before the break equals $\operatorname{Lag}_{\mathrm{B} 1, \mathrm{~B} 2}$ and the sum of idle times after the break equals $\operatorname{Lag}_{\mathrm{B} 2, \mathrm{~B} 3}+\mathrm{Lag}_{\mathrm{B} 3, \mathrm{~B} 4}$. (Figure 1). Therefore, activity B1 must be postponed from its early start date by the sum of idle times before the work break $\left(\operatorname{Lag}_{\mathrm{B} 1, \mathrm{~B} 2}\right)$ in order to achieve continuous resource utilization from activity B1 to B2, as shown in Figure 3. After the completion of B2, the resource will take a break for a period equal to the sum of idle times at and after the work break location $\left(\operatorname{Lag}_{\mathrm{B} 2, \mathrm{~B} 3}+\mathrm{Lag}_{\mathrm{B} 3, \mathrm{~B} 4}\right)$ to achieve continuity between activities B3 and B4. The introduction of a work break between B2 and B3 reduces the increased project duration due to continuity constraints from 135 days in Figure 2 to 115 days in Figure 3.

The example in Figures 1, 2 and 3 outlines the process of scheduling repetitive projects with deterministic activity durations. To introduce work breaks within repetitive projects with probabilistic activity durations, it is necessary to use the sequence step algorithm (SQS-AL) by Ioannou and Srisuwanrat (2006) with some minor modifications. An important change is the need to split the parameter Crew Idle Time (CIT) for each repetitive activity into two parts: (a) idle time before the work break, and (b) idle time after the work break. Similarly, the parameter Crew Lead Time (CLT) must also be split into two parts as outlined below.

\section{SEQUENCE STEP ALGORITHM (SQS-AL)}

The sequence step algorithm (SQS-AL) is a probabilistic scheduling method for repetitive projects introduced by Ioannou and Srisuwanrat (2006) to extend repetitive project scheduling to activities with probabilistic durations. Several concepts introduced in SQS-AL are used in the following sections and are prerequisites for a thorough understanding of the methodology for calculating optimal work breaks using the modified sequence step algorithm.

\section{CALCULATION OF WORK BREAK IN SQS-AL}

In the sequence step algorithm (SQS-AL), there are two main variables, the Crew Idle Time (CIT) and the Crew Lead Time (CLT). CIT is a state variable that collects idle time for an activity (e.g., B) and CLT is a decision variable that determines the fist start date of the activity (e.g., B1).

Crew idle time (CIT) is the total idle time experienced by a crew from the time it arrives to the site (originally at time zero) until the corresponding work activity is finished. Under the assumption that there is no work break, each repetitive activity is associated with a single crew idle time (CIT) that collects its total idle time from each simulated project replication.

When a work break is introduced within a repetitive activity, however, its crew idle time (CIT) is split in two: the idle time before the work break (CIT1) and the idle time after the work break (CIT2). In this case, we have:

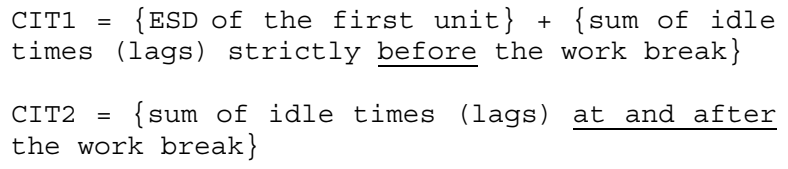

In Figure 3, for example, a work break is introduced between B2 and B3. Thus, CIT1 measures idle time from project start to the end of B2 and CIT2 measures idle time from the end of B2 to the end of B4 (Figure 1):

$\operatorname{CIT1}_{\mathrm{B}}=\mathrm{ESD}_{\mathrm{B} 1}+\operatorname{Lag}_{\mathrm{B} 1, \mathrm{~B} 2}$
$\mathrm{CIT} 2_{\mathrm{B}}=\operatorname{Lag}_{\mathrm{B} 2, \mathrm{~B} 3}+\operatorname{Lag}_{\mathrm{B} 3, \mathrm{~B} 4}$

In this example, activity durations are deterministic and the Crew Lead Time for resource $B$ is equal to $C I T 1_{B}$. I.e., resource $\mathrm{B}$ should start $\mathrm{B} 1$ at $\mathrm{CLT}_{\mathrm{B}}=\mathrm{CIT}_{\mathrm{B}}$ and work 


\section{Ioannou and Srisuwanrat}

continuously until it finishes B2. At that point, the resource should take a work break and leave the site for a duration of CIT2 $2_{\mathrm{B}}$. At the end of the break it should return to complete activities B3 and B4.

For projects with probabilistic activity durations, crew idle time must also be grouped into CIT1 and CIT2. However, the means of determining the start date in the first unit (CLT) and the duration of the work break need to be modified to allow for uncertainty and the resulting variability in the data.

In SQS-AL, for example, when processing sequence step 2 (i.e., the sequence step of activity B), CIT $1_{B}$ and $\mathrm{CIT} 2_{\mathrm{B}}$ are collected in every project replication. These CIT are different from one replication to the next because of randomness in activity durations. After a user-specified number of replications are simulated, the collected samples of CIT1 and CIT2 are summarized in histograms based on relative frequency (Ioannou and Srisuwanrat 2006).

At this point, the user does not have single deterministic values for CIT1 and CIT2 to use as Crew Lead Times CLT1 and CLT2. Instead the user must choose a desired confidence level (probability) and use that to select the corresponding Crew Lead Times for before and after the break (CLT1 and CLT2) from the corresponding histograms for CIT1 and CIT2.

In this case, CLT1 is the selected start time for the activity in the first unit (e.g., B1), whereas CLT2 is the selected work break duration. After the completion of the unit prior to the work break (e.g. the finish date of B2), resource B must take a break and leave the site for a duration $\mathrm{CLT}_{\mathrm{B}}$ before coming back. Delaying the work in the unit right after the break by $\mathrm{CLT} 2_{\mathrm{B}}$, ensures that when resource $B$ returns it should be able to work continuously and without idle time with probability equal to the chosen confidence level. A detailed description of how to determine CLT for a user-specified confidence level from a given a CIT histogram appears in (Ioannou and Srisuwanrat 2006).

Using this approach, the work break has a fixed duration equal to CLT2, but the start and end of the break are uncertain. In certain cases, it may be desirable to define CIT2 so that it does not specify a fixed work break dura- tion, but rather provides a specific return date for the resource to resume work after the break. In order to determine such a specific return date, CIT2 needs to be modified as follows:

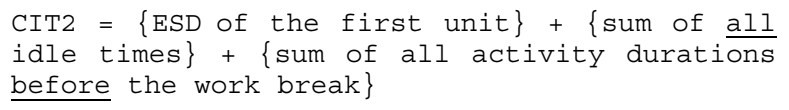

For example in Figure 1, the crew idle time for the specific return date of resource $\mathrm{B}\left(\mathrm{CIT} 2_{\mathrm{B}}\right)$ is:

$$
\mathrm{CIT}_{\mathrm{B}}=\mathrm{ESD}_{\mathrm{B} 1}+\left\{\operatorname{Lag}_{\mathrm{B} 1, \mathrm{~B} 2}+\operatorname{Lag}_{\mathrm{B} 2, \mathrm{~B} 3}+\operatorname{Lag}_{\mathrm{B} 3, \mathrm{~B} 4}\right\}+\left\{\mathrm{T}_{\mathrm{B} 1}+\mathrm{T}_{\mathrm{B} 2}\right\}
$$

The procedure for summarizing samples of CIT2 into a histogram and for selecting CLT2 is the same as described above. The only difference is that this CLT2 is a specific return date after the work break whereas before it represented the work break duration. Thus, the duration of the break is uncertain and equal to CLT2 (fixed) minus the end date for the work unit before the break (random).

\section{EXAMPLE PROJECT}

The methodology for the optimal introduction of work breaks will be demonstrated using an example project comprised of 9 activities with probabilistic durations that repeat over 10 non-identical work units. The simulation model, the sequence step algorithm, and the introduction of work breaks have been implemented using the Stroboscope discrete-event simulation system.

The precedence network for each of the 10 work units in the example project is the one shown in Figure 4. The quantities of work for each activity, however, are different in each unit as shown in Table 2. Moreover, each activity is performed by a different crew that has its own uncertain production rate. The production rate for each crew follows a normal distribution with the mean and standard deviation shown in Table 2 . Thus, activity durations vary from unit to unit because of different work quantities and because of randomness in production rates.

For this example, 1000 replications were simulated for each stage of SQS-AL. A confidence level of $80 \%$ was

Table 2: Resource daily production rates and activity work amounts in each repetitive unit

\begin{tabular}{|c|c|c|c|c|c|c|c|c|c|c|c|c|c|}
\hline \multirow{2}{*}{ Activity } & Resource Daily & \multicolumn{10}{|c|}{ Repetitive Unit } \\
\cline { 4 - 13 } & Production Rate & 1 & 2 & 3 & 4 & 5 & 6 & 7 & 8 & 9 & 10 \\
\hline Name & Mean & SD & \multicolumn{10}{|c|}{ Work Amount } \\
\hline A & 20 & 2.0 & 200 & 200 & 200 & 200 & 200 & 200 & 400 & 400 & 400 & 400 \\
\hline B & 30 & 3.0 & 150 & 150 & 100 & 100 & 100 & 100 & 100 & 100 & 100 & 100 \\
\hline C & 30 & 3.0 & 250 & 200 & 200 & 250 & 300 & 200 & 350 & 400 & 200 & 350 \\
\hline D & 15 & 1.5 & 300 & 400 & 400 & 450 & 300 & 300 & 250 & 250 & 250 & 400 \\
\hline E & 20 & 2.0 & 150 & 150 & 150 & 150 & 150 & 150 & 200 & 200 & 200 & 200 \\
\hline F & 25 & 2.5 & 350 & 400 & 300 & 350 & 150 & 200 & 400 & 250 & 300 & 250 \\
\hline G & 30 & 3.0 & 150 & 150 & 150 & 150 & 300 & 250 & 300 & 300 & 300 & 450 \\
\hline H & 20 & 2.0 & 200 & 300 & 300 & 200 & 250 & 400 & 300 & 400 & 300 & 250 \\
\hline J & 15 & 1.5 & 200 & 200 & 200 & 200 & 200 & 200 & 300 & 300 & 300 & 300 \\
\hline
\end{tabular}




\section{Ioannou and Srisuwanrat}

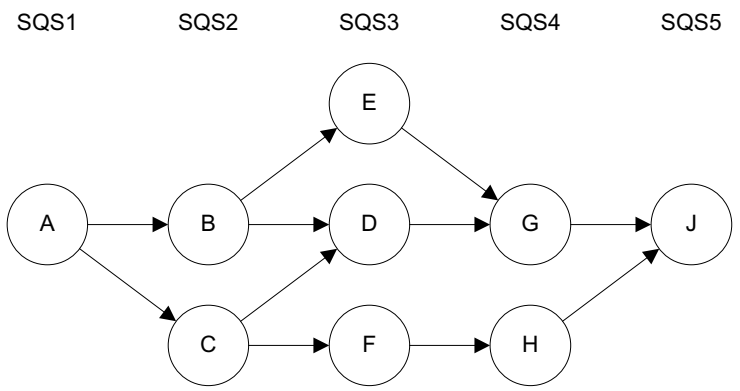

Figure 4: Precedence diagram for a single project unit.

used to choose the crew lead times CLT1 and CLT2 as needed for each activity. In this example, CLT2 represents a specific return date after a work break.

Figure 5 shows the production diagram for one CPM early-start schedule out of 1000 replications. Crews are assumed to arrive and start work in the first unit exactly when needed (no idle time) and activities start as soon as their predecessors in the same unit are complete. This produces the shortest possible average project duration of 277 days. As expected, however, allowing activities to start as early as possible results in a total average idle time between repetitive units of 438 days. Out of the nine activities, only A and D do not have any interruptions.

Figure 6 shows the project schedule derived from SQS-AL. To eliminate idle time, activity starts are delayed by their respective Crew Lead Times, CLT1, as shown in Table 3, using a confidence level of $80 \%$. The resulting average total idle time for the project is only 1 day but the average project duration has grown to 449 days. Thus, to eliminate resource idle time, project duration had to increase by 172 days or about $60 \%$. It may be hard to justify to management or the project owner to delay project completion that much in order to eliminate idle time.

We shall now investigate the decrease in project duration due to the introduction of one or more work breaks. As shown in Figure 6, there are 5 repetitive activities on the controlling sequence of this schedule (A, B, D, G, and J) and only these activities are candidates for work breaks. Once the activities on the controlling sequence are identified, we can compare their relative production rates.

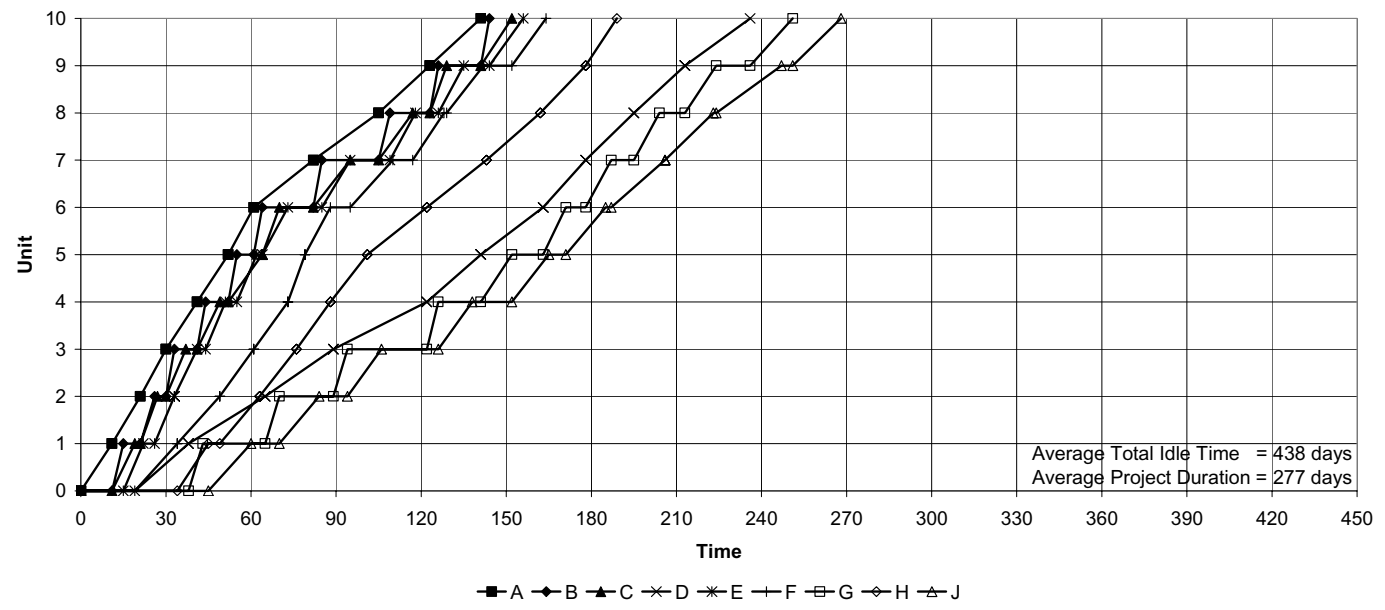

Figure 5: Early-start schedule has project duration of 277 days but also has 438 days of idle time.

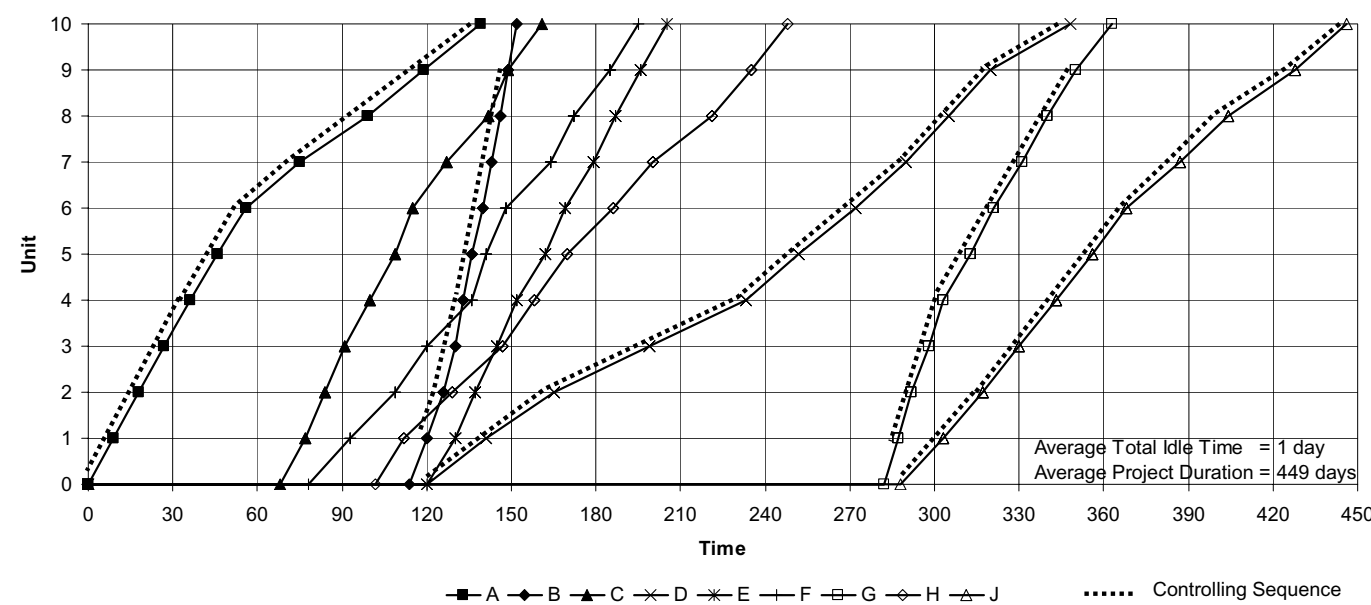

Figure 6: SQS-AL with no work breaks has project duration of 449 days. 


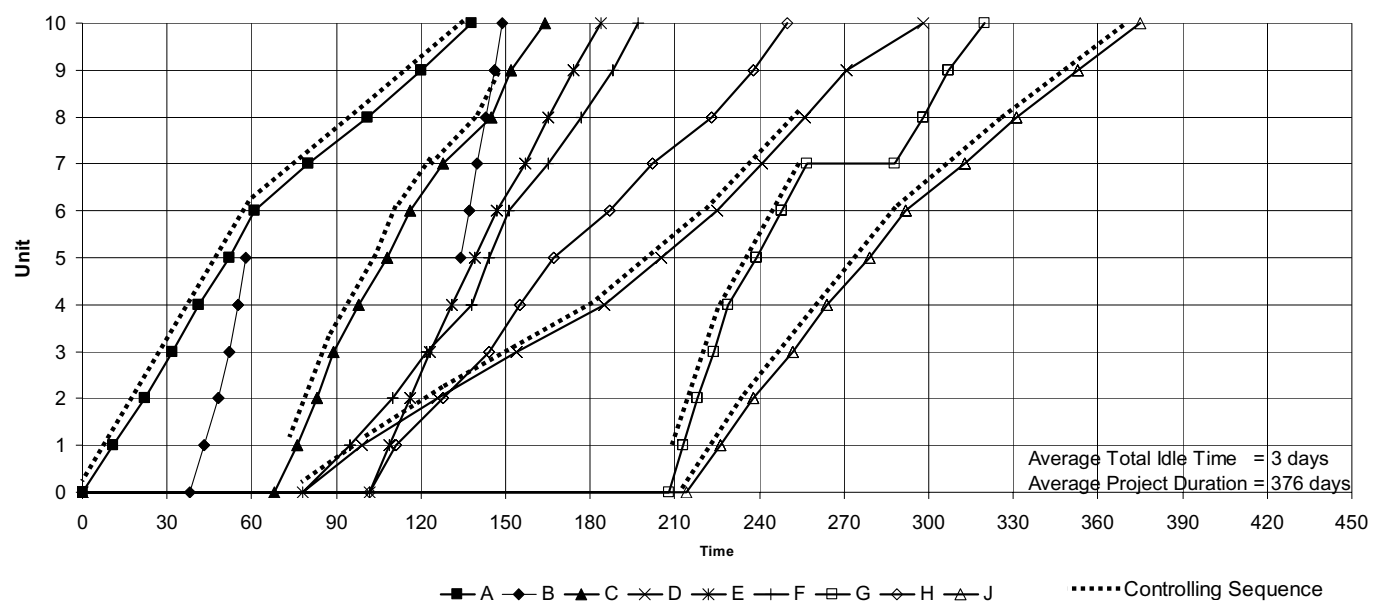

Figure 7: SQS-AL schedule with two work breaks has average project duration of 376 days.

Table 3: SQS-AL schedule with no work breaks.

\begin{tabular}{|c|c|c|c|}
\hline Activity & $\begin{array}{c}\text { Crew } \\
\text { Arrival Date } \\
\text { (CLT1) }\end{array}$ & $\begin{array}{c}\text { Work } \\
\text { Break } \\
\text { Location }\end{array}$ & $\begin{array}{c}\text { Crew } \\
\text { Return Date } \\
\text { (CLT2) }\end{array}$ \\
\hline A & 0 & - & - \\
\hline B & 114 & - & - \\
\hline C & 68 & - & - \\
\hline D & 120 & - & - \\
\hline E & 120 & - & - \\
\hline F & 78 & - & - \\
\hline G & 282 & - & - \\
\hline H & 102 & - & - \\
\hline J & 288 & - & - \\
\hline
\end{tabular}

Of the 5 activities on the controlling sequence, only activities B and G satisfy the two necessary conditions for shortening project duration, i.e., a converging relationship with their predecessor and a diverging relationship with their successor. Activity B, for example, has a converging relationship with activity A (its predecessor) and a diverging relationship with activity $\mathrm{C}$ (its successor).

To determine the best work break location for activity $\mathrm{B}$ that yields the shortest project duration, we must evaluate nine possible positions at the finish dates of B1, B2, and so on until B9. For each location we collect crew idle times before and after the prospective work break (CLT1 and CLT2) to determine the start date of B1 and the specific return date for the resource after the break.

The same process is performed for activity $G$ at the finish dates of G1, G2, and so on until G9. After all possible work break positions in activity B and $\mathrm{G}$ are evaluated, the results indicate that the two best work break locations in $\mathrm{B}$ and $\mathrm{G}$ are at the completion of B5 and G7, as shown in Figure 7. A work break at the completion of G7 shortens project duration by 39 days. A work break at the completion of B5 shortens project duration by 34 days.

Applying the two work breaks together shortens the average project duration by 73 days, from 449 to 376 days. The average total idle time increases slightly from 1 to 3 days. Table 4 shows CLT1 and CLT2 for each activity.

Table 4: SQS-AL schedule with two work breaks.

\begin{tabular}{|c|c|c|c|}
\hline Activity & $\begin{array}{c}\text { Crew } \\
\text { Arrival Date } \\
\text { (CLT1) }\end{array}$ & $\begin{array}{c}\text { Work } \\
\text { Break } \\
\text { Location }\end{array}$ & $\begin{array}{c}\text { Crew } \\
\text { Return Date } \\
\text { (CLT2) }\end{array}$ \\
\hline A & 0 & - & - \\
\hline B & 38 & B5-B6 & 134 \\
\hline C & 68 & - & - \\
\hline D & 78 & - & - \\
\hline E & 102 & - & - \\
\hline F & 78 & - & - \\
\hline G & 208 & G7-G8 & 288 \\
\hline H & 102 & - & - \\
\hline J & 214 & - & - \\
\hline
\end{tabular}

It is important to note that the introduction of a work break in activity $\mathrm{G}$ does not change the status of activity $\mathrm{B}$ on the controlling sequence, and vice versa. Thus, the locations that satisfy the necessary conditions for reducing project duration remain the same. Therefore, it is allowable to break both activities in one step. Otherwise, we should introduce a break only in activity $\mathrm{G}$ (as the most effective in reducing project duration) and then identify new possible work break positions on the resulting controlling sequence.

In Figure 7, resource B is scheduled to work continuously from B1 to the end of B5. At that point it should take a break and return to the site to start work on B6 on day 


\section{Ioannou and Srisuwanrat}

134. Resource $\mathrm{G}$ is scheduled to work continuously from G1 to the end of G7. Then resource G should take a break and come back on day 288. Clearly, the work break durations for B and $\mathrm{G}$ are not fixed, but depend on when the activities finish the unit prior to their respective breaks.

A comparison of Figures 6 and 7 shows that activity B is no longer on the controlling sequence after the introduction of a work break. Instead, activity $\mathrm{C}$ becomes the activity in sequence step 2 that is on controlling sequence. On the other hand, activity $\mathrm{G}$ in sequence step 4 is still on the controlling sequence. Thus, the controlling sequence for the new schedule in Figure 7 includes five activities (A, C, $\mathrm{D}, \mathrm{G}$, and J).

A comparison of the relative production rates of the five activities on the controlling sequence in Figure 7 indicates that only activities $\mathrm{C}$ and $\mathrm{G}$ have converging relationships with their predecessors and diverging relationships with their successors. Since activity G has just been evaluated for a work break in the previous step, it is not necessary to consider it again in this step. We only need to evaluate possible work break locations for activity $\mathrm{C}$.

At this point it should be noted that sometimes the converging or diverging relationships between activities on the controlling sequence are not evident. For example, in Figure 7 the converging relationship between activity $\mathrm{C}$ and its predecessor, activity $\mathrm{A}$, is not obvious. In such cases, it is necessary to introduce and test a work break (e.g., in C) to see if it would indeed shorten the project.

There are nine possible work break locations for activity $\mathrm{C}$, i.e., at the end of $\mathrm{C} 1, \mathrm{C} 2$, and so on to the end of $\mathrm{C} 9$. The best location is at the completion of $\mathrm{C} 4$ which shortens the project duration by 34 days. The resulting project schedule with work breaks in activities B, C, and $G$, is shown in Figure 8. The crew lead times, CLT1 and CLT2, for the three work break locations appear in Table 5. Overall, the introduction of the three work breaks in B, C, and $\mathrm{G}$, reduces average project duration to 342 days with an average total idle time of only 3 days. It should be noted that $\mathrm{CLT}_{\mathrm{G}}$ is reduced from 288 in Table 4 to 254 Table 5. The introduction of a work break at $\mathrm{C} 4$ allows its successor activities, including G8 (the first activity after the break), to start earlier and reduces project duration by 34 days.

Table 5: SQS-AL schedule with three work breaks.

\begin{tabular}{|c|c|c|c|}
\hline Activity & $\begin{array}{c}\text { Crew } \\
\text { Arrival Date } \\
\text { (CLT1) }\end{array}$ & $\begin{array}{c}\text { Work } \\
\text { Break } \\
\text { Location }\end{array}$ & $\begin{array}{c}\text { Crew } \\
\text { Return Date } \\
\text { (CLT2) }\end{array}$ \\
\hline A & 0 & - & - \\
\hline B & 38 & B5-B6 & 134 \\
\hline C & 22 & C4-C5 & 98 \\
\hline D & 44 & - & - \\
\hline E & 102 & - & - \\
\hline F & 60 & - & - \\
\hline G & 174 & G7-G8 & 254 \\
\hline H & 84 & - & - \\
\hline J & 180 & - & - \\
\hline
\end{tabular}

Table 6 is a summary of the average project duration and the average total idle time from CPM, and SQS-AL with zero, one, two and three work breaks.

Table 6: Project duration and idle time summary.

\begin{tabular}{|c|c|c|c|}
\hline Method & $\begin{array}{c}\text { Average } \\
\text { Project } \\
\text { duration }\end{array}$ & $\begin{array}{c}\text { Average } \\
\text { Total Idle } \\
\text { Time }\end{array}$ & $\begin{array}{c}\text { Work } \\
\text { Break } \\
\text { Positions }\end{array}$ \\
\hline CPM & 277 & 444 & - \\
\hline SQS-AL & 449 & 1 & - \\
\hline SQS-AL & 410 & 3 & G7 \\
\hline SQS-AL & 376 & 3 & G7,B5 \\
\hline SQS-AL & 342 & 3 & G7,B5,C4 \\
\hline
\end{tabular}

Clearly, SQS-AL is quite effective in reducing the average crew idle time from 444 days to 1 day to save the

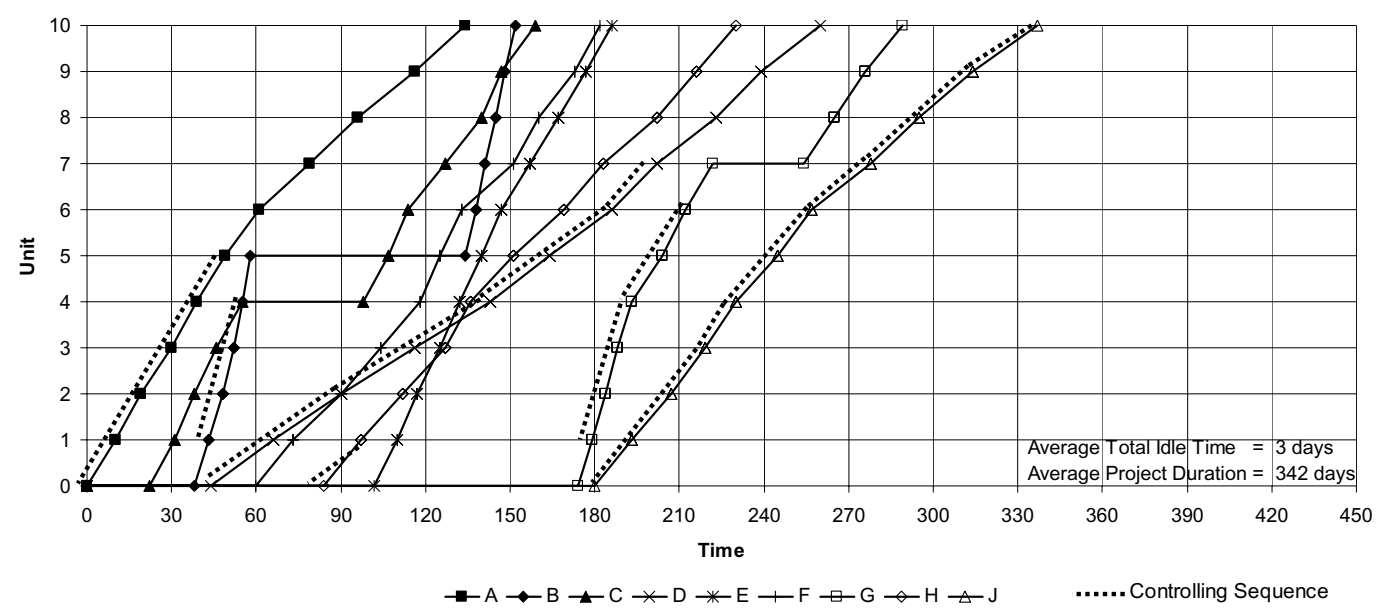

Figure 8: With 3 work breaks, SQS-AL Schedule results in project duration of 342 days 


\section{Ioannou and Srisuwanrat}

cost of having idle workers on site. However, it also increases project duration significantly, from 277 to 449 days (or from 9 to 15 months). The optimal introduction of work breaks reduces project duration with almost no resource idle time. One-by-one, the introductions of work breaks at the end of $\mathrm{G} 7, \mathrm{~B} 5$, and $\mathrm{C} 4$, reduce average project duration by 39,34 , and 34 days respectively. In the final schedule, the three work breaks result in an average project duration of 342 days (11.5 months) with idle time of just 3 days. In other words, the average project duration increases by 2.5 months from the CPM schedule while the 15 months of average crew idle time is almost completely eliminated.

Moreover, a comparison of the SQS-AL schedule with no work breaks (Table 3 and Figure 6) and the SQS-AL schedule with three work breaks (Table 5 and Figure 8) shows that the introduction of breaks improves the SQSAL by 3.5 months. Thus, the optimal introduction of work breaks is an effective strategy for shortening the increased project duration that results from resource continuity constraints.

\section{SUMMARY AND CONCLUSION}

This paper presents the methodology for the introduction of optimal work breaks to shorten project duration in repetitive scheduling under uncertainty by relaxing the appropriate resource continuity constraints while minimizing crew idle time. Having resources (crews) work continuously and with no interruptions requires that activities be delayed beyond their early start dates, which sometimes may lengthen project duration significantly. Therefore, the tradeoff between maintaining and relaxing resource continuity constraints merits careful consideration.

The optimal introduction of work breaks to relax the appropriate resource continuity constraints by the correct amount has been presented and applied to an example of probabilistic repetitive project scheduling. Employing the concepts of control points, the controlling sequence, and relative production rates, the presented methodology and the example demonstrate analytical procedures for determining whether the introduction of a work break in a repetitive activity would shorten project duration. Moreover, we have presented the sequential methodology for determining the location of optimal work breaks, and the duration of the breaks (which yield uncertain crew return dates) or the determination of fixed return dates (which yield uncertain break durations). The presented methodology is applicable to both deterministic and probabilistic scheduling of repetitive projects.

\section{ACKNOWLEDGEMENTS}

The writers would like to thank Sirarat Sarntivijai, graduate student at the University of Michigan for her help.

\section{REFERENCES}

Harris, R.B. 1978. Precedence and Arrow Networking Techniques for Construction. John Wiley \& Sons, Inc., New York, ISBN 0-471-04123-8, 50-51.

Harris, R.B., and Ioannou, P.G. 1998. Scheduling projects with repeating activities. Journal of Construction Engineering and Management, ASCE, July/August 1998, 269-278

Ioannou, P.G., and Likhitruangsilp, V. 2005. Simulation of multiple-drift tunnel construction with limited resources, In Proceedings of the 2005 Winter Simulation Conference, ed. M.E. Kuhl, N.M. Steiger, F.B. Armstrong, and J.A. Joines, 1483-1491.

Ioannou, P.G., and Srisuwanrat, C. 2006. Sequence Step Algorithm for Continuous Resource Utilization in Probabilistic Repetitive Project, In Proceedings of the 2006 Winter Simulation Conference, ed. L. F. Perrone, F. P. Wieland, J. Liu, B. G. Lawson, D. M. Nicol, and R. M. Fujimoto, 1731-1740.

Martinez, J.C. 1996. STROBOSCOPE: State and resource based simulation of construction processes. Doctoral Dissertation, Dept. of Civil and Environ. Engineering, University of Michigan, Ann Arbor, Michigan.

Martinez, J.C. and P.G. Ioannou. 1999. General Purpose Systems For Effective Construction Simulation. Journal of Construction Engineering and Management, ASCE, (125)4, July-August 1999.

\section{AUTHOR BIOGRAPHIES}

PHOTIOS G. IOANNOU is Professor of Civil and Environmental Engineering at the University of Michigan. He received a Dipl. Civil Eng. from the National Technical University of Athens, Greece, in 1979, and a SMCE and Ph.D. in Civil Engineering from MIT in 1981 and 1984. From 1989-1995 he served as Chairman of the Computing in Construction Technical Committee of the ASCE. He codeveloped three construction simulation systems: UMCYCLONE with R.I. Carr (1989), COOPS with L.Y. Liu (1991), and STROBOSCOPE with J.C. Martinez (1996). His research is in construction engineering and management, and in particular in decision support systems and construction process modeling and simulation. His e-mail is <photios@umich.edu> and his website can be found at <wWw. cem. umich. edu/Ioannous.

CHACHRIST SRISUWANRAT is Ph.D. Candidate in Construction Engineering Management at the University of Michigan. His research is in the area of resource utilization and construction simulation under the direction of P.G. Ioannou. His e-mail is <csrisuwa@umich.edu>. 